\title{
Bidirectional Soft-Switching Converter-fed Dc Motor Drives
}

\author{
K.T. Chau, T.W. Ching and C.C. Chan \\ Department of Electrical and Electronic Engineering, \\ The University of Hong Kong, Pokfulam, HONG KONG
}

\begin{abstract}
Two new soft-switching dc-dc converters, with the capabilities of bidirectional power flow, and softswitching (either zero-voltage transition or zerocurrent transition) are developed for dc motor drives. The proposed bidirectional zero-voltage-transition converter possesses the definite advantages that both main transistors and rectifiers can switch with zerovoltage switching (ZVS) and unity device stresses during motoring and regenerating modes of operation. While both the main and auxiliary switches of the bidirectional zero-current-transition converter can operate with zero-current switching (ZCS) and minimum voltage / current stress. These converters are particularly useful for de traction systems in which both motoring and regenerative braking are desired to have high efficiency.
\end{abstract}

\section{INTRODUCTION}

Nowadays, the use of low-inductance dc motors is becoming attractive because of the advantages of higher power density, lower rotor inertia, smoother commutation and lower manufacturing costs. However, it usually suffers from high current ripples, resulting in increased losses and switching stresses. To alleviate this problem, the switching frequency of power converters needs to be increased from less than one to over one hundred kilohertz. With available power devices technologies, hard-switching PWM converters operating at such high frequencies impose high switching losses and switching stresses.

Recently, a number of soft-switching techniques, providing zero-voltage switching (ZVS) or zero-current switching (ZCS) conditions, have been successfully developed for switched-mode power supplies (SMPS) [1]-[5]. Surprisingly, the development of soft-switching converters for dc motor drives has been very little. Even so, it has been assumed that those being developed for SMPS can be directly applicable [6]. Until recently, a systematic evaluation of available soft-switching converters for dc motor drives has been carried out [7]. As a result, these soft-switching converters cannot satisfy the operating requirements of dc motor drives. Apart from suffering excessive voltage and current stresses, they cannot handle bidirectional power flow during regenerative braking.
Different to SMPS, dc motor drives especially for traction applications need regenerative braking. Technically, the dc motor operates as a generator to convert the kinetic energy into the electrical energy while the converter must allow for bidirectional power flow to restore the energy to the power networks or battery systems. This energy-recovery feature is particularly attractive to electric railways and batterypowered electric vehicles.

In this paper, two new soft-switching dc-dc converters, with the capabilities of bidirectional power flow, either with zero-voltage-transition (ZVT) or zerocurrent-transition (ZCT), are proposed for dc motor drives. Their principle of operation during both motoring and regenerative modes, as well as experimental results will be given.

\section{PRINCIPLE OF OPERATION - BIDIRECTIONAL ZVT CONVERTER}

Fig. 1 shows the circuit diagram of the proposed bidirectional ZVT converter for dc motor drives. It differs from a conventional bidirectional PWM converter, since the addition of a resonant inductor Lr, a resonant capacitor $\mathrm{Cr}$ and two auxiliary switches $\mathrm{Sa}$ and $\mathrm{Sa}$.

The operating waveforms in the motoring mode are shown in Fig. 2, while the corresponding topological modes are illustrated in Fig. 3. Similarly, the operating waveforms in the regenerating mode are shown in Fig. 4, while the corresponding topological stages are illustrated in Fig. 5. As shown in Figs. 3 and 5 , both modes exist seven operating stages within one switching cycle.

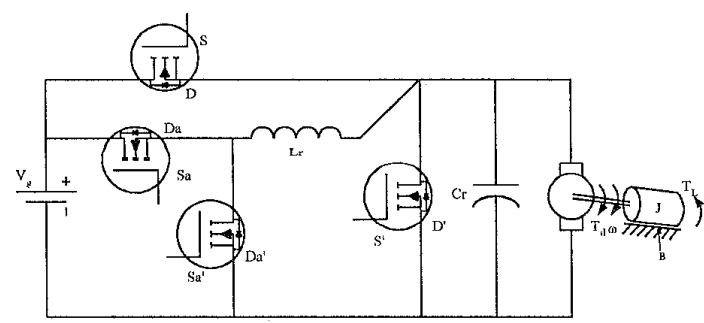

Fig. 1. Proposed bidirectional ZVT converter. 

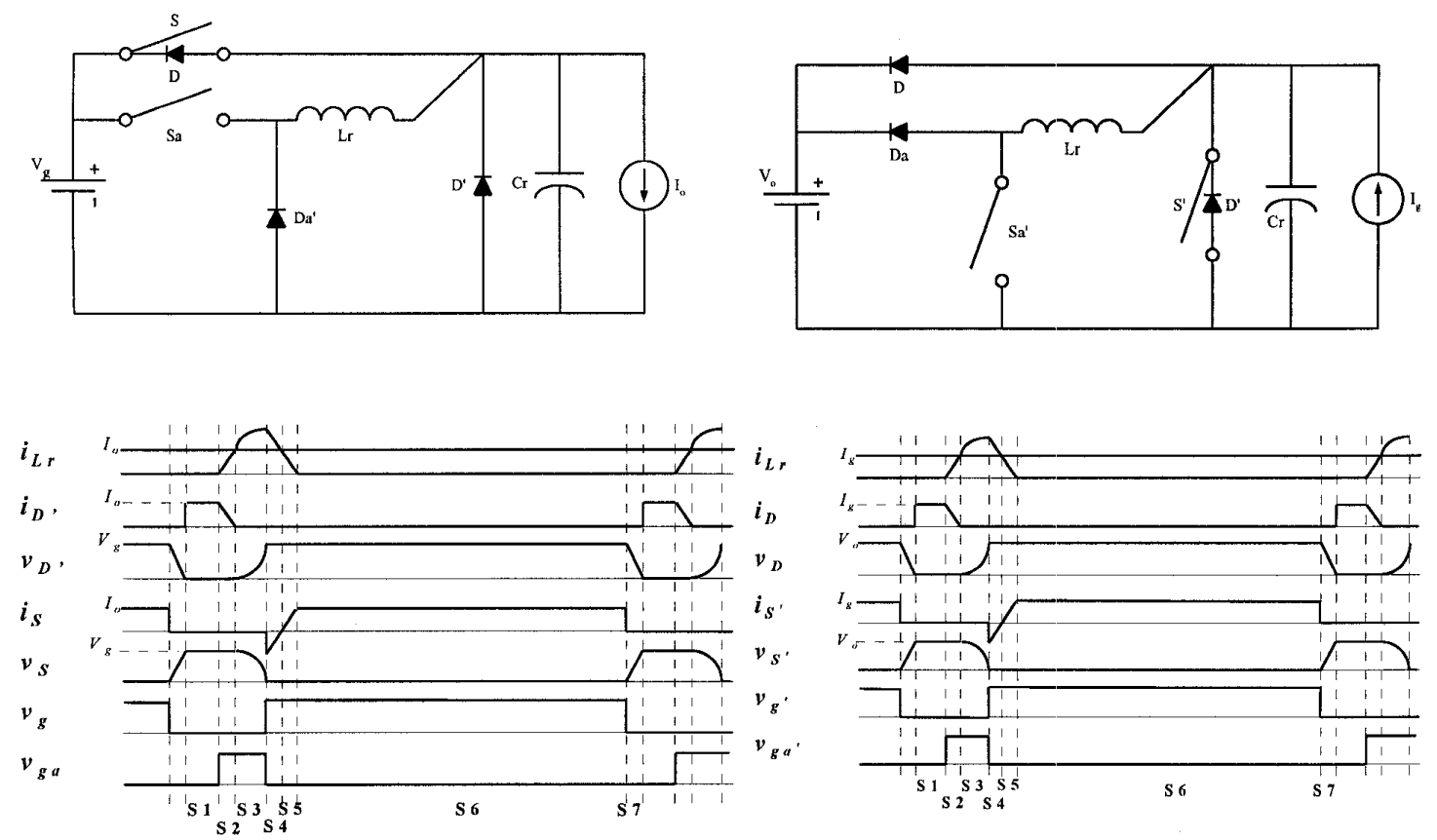

Fig. 2. Equivalent circuit and key waveforms of bidirectional ZVT converter during motoring mode.

Fig. 4. Equivalent circuit and key waveforms of bidirectional ZVT converter during regenerating mode.

(a)
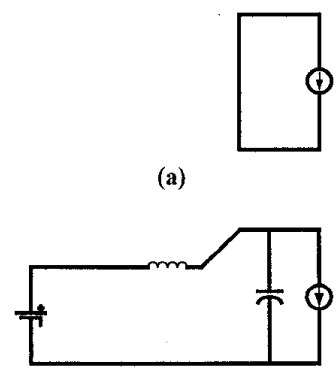

(c)

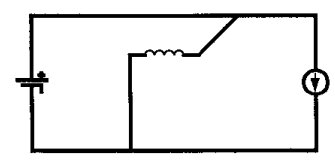

(e)

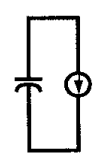

(g)

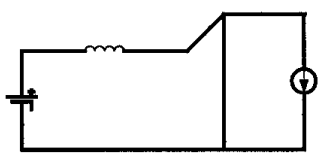

(b)

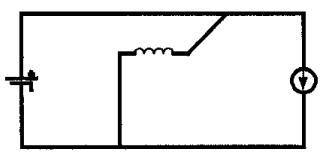

(d)

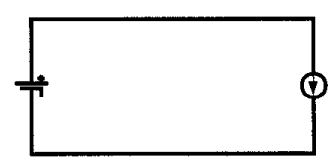

(f)

Fig. 3. Seven topological stages of bidirectional ZVT converter during motoring mode.

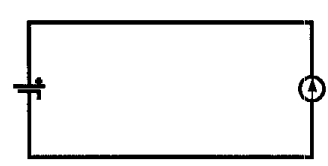

(a)

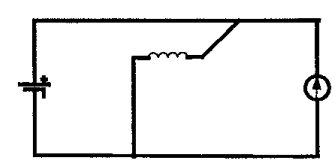

(b)

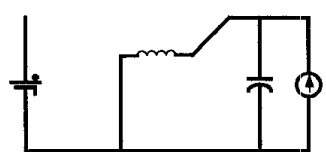

(c)

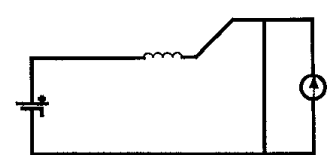

(d)

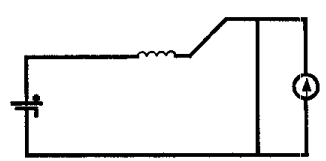

(e)

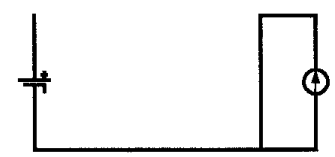

(f)

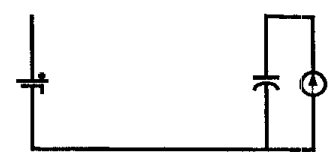

(g)

Fig. 5. Seven topological stages of bidirectional ZVT converter during regenerating mode. 


\subsection{Motoring Mode (Figs. $2 \&$ 3)}

(a) Stage $1\left[T_{0}-T_{1}\right]$ : It is a freewheeling mode via $\mathrm{D}^{\prime}$.

(b) Stage $2\left[T_{1}-T_{2}\right]: \quad \mathrm{S}_{\mathrm{a}}$ is turned on. $i_{L r}$ increases according to the slope of $V_{g} / L r$.

(c) Stage $3\left[T_{2}-T_{3}\right]$ : When $i_{L r}=I_{O}, \mathrm{D}^{\prime}$ is turned off with ZVS, and $\mathrm{Lr}$ and $\mathrm{Cr}$ start resonating.

(d) Stage $4\left[T_{3}-T_{4}\right]$ : When $v_{c_{r}}$ reaches $V_{g}, \mathrm{~S}$ is turned on with ZVS. $\mathrm{S}_{\mathrm{a}}$ is turned off to recover the stored energy in $\mathrm{Lr}$ to the source. Then $i_{L r}$ flows through $\mathrm{D}_{\mathrm{a}}{ }^{\prime}$ and decreases linearly with a slope of $V_{g} / L r$.

(e) Stage $5\left[T_{4}-T_{5}\right]$ : $i_{L r}$ keeps decreasing while $i_{S}$ increasing until $i_{L r}$ reaches zero at $T_{5}$ and $\mathrm{D}_{\mathrm{a}}{ }^{\prime}$ becomes off.

(f) Stage $6\left[T_{5}-T_{6}\right]$ : It is a powering mode.

(g) Stage $7\left[T_{6}-T_{7}\right]: I_{O}$ discharges $\mathrm{Cr}$ linearly with a slope of $\mathrm{I}_{O} / \mathrm{Cr}$ until $v_{C}$, equals zero at $T_{7}$, and eventually $D^{\prime}$ becomes conducting.

\subsection{Regenerating Mode (Figs. 4 \& 5)}

(a) Stage $1\left[T_{0}-T_{1}\right]: \mathrm{D}$ is conducting, a regenerating mode.

(b) Stage $2\left[T_{1}-T_{2}\right]: \mathrm{S}_{\mathrm{a}}^{\prime}$ is turned on. ${ }^{\mathrm{Lr}}$ increases with the slope of $V_{g} / L r$.

(c) Stage $3\left[T_{2}-T_{3}\right]$ : When $i_{L r}$ reaches $I_{g}$ at $T_{2}, \mathrm{D}$ is turned off with ZVS, and $\mathrm{Lr}$ and $\mathrm{Cr}$ start resonating

(d) Stage $4\left[T_{3}-T_{4}\right]$ : When $v_{c}$, reaches zero, $\mathrm{S}^{\prime}$ is turned on with ZVS. $S_{\mathrm{a}}{ }^{\prime}$ is turned off to recover the stored energy in $\mathrm{Lr}$ to the source. Then $i_{L r}$ flows through $\mathrm{D}_{\mathrm{a}}$ and decreases linearly.

(e) Stage $5\left[T_{4}-T_{5}\right]$ : i ${ }^{2}{ }_{r}$ keeps decreasing and is' increasing until i $L_{r}$ reaches zero at $T_{5} . \mathrm{D}_{\mathrm{a}}$ becomes off.

(f) Stage $6\left[T_{5}-T_{6}\right]:$ It is a freewheeling mode.

(g) Stage $7\left[T_{6}-T_{7}\right]: \quad I_{g}$ charges $\mathrm{Cr}$ linearly with a slope of $I_{g} / C r$ until $v_{C}$, equals $V_{g}$ at $T_{7}$, and eventually $\mathrm{D}$ becomes conducting.

\section{PRINCIPLE OF OPERATION - BIDIRECTIONAL ZCT CONVERTER}

Fig. 6 shows the circuit diagram of the proposed bidirectional ZCT converter for DC motor drives. Compared with the conventional bidirectional PWM converter, the proposed converter needs additional components - - a resonant inductor $L r$, a resonant capacitor $\mathrm{Cr}$ and two auxiliary switches $\mathrm{Sa}$ and $\mathrm{Sa}^{\prime}$. It should be noted that these additional components are inevitable for soft-switching operation, and the corresponding hardware count is minimum.
The operating waveforms in the motoring mode are shown in Fig. 7, while the corresponding topological stages are illustrated in Fig. 8. Similarly, the operating waveforms in the regenerating mode are shown in Fig. 9, while the corresponding topological stages are illustrated in Fig. 10. As shown in Figs. 9 and 10, both modes exist nine stages within one switching cycle.

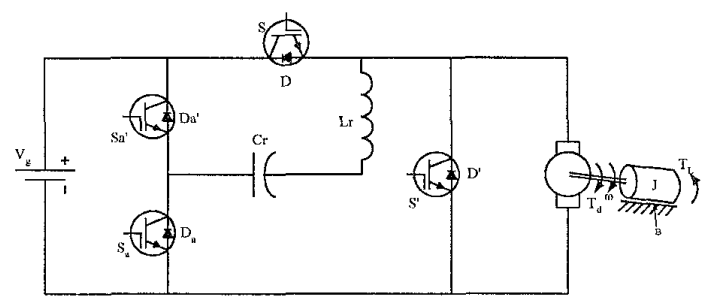

Fig. 6. Proposed bidirectional ZCT converter
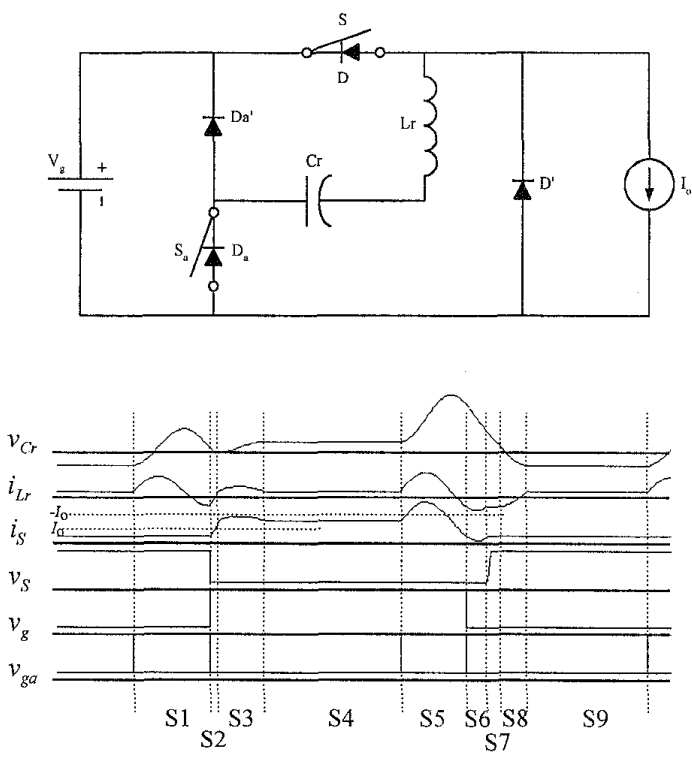

Fig. 7. Equivalent circuit and key waveforms of bidirectional ZCT converter during motoring mode.

\subsection{Motoring Mode (Figs. 7 \& 8)}

(a) Stage $1\left[T_{0}-T_{1}\right]: \quad \mathrm{S}_{\mathrm{a}}$ is turned on and $\mathrm{Lr}$ and $\mathrm{Cr}$ start resonating. When $i_{L r}$ increases from zero to peak and then decreases toward zero and changes direction. $i_{L r}$ reaches $-I_{\mathrm{o}}$ at $T_{1}$ and the antiparallel diode of $\mathrm{S}_{\mathrm{a}}$ becomes on. 
(b) Stage $2\left[T_{1}-T_{2}\right]: \mathrm{S}_{\mathrm{a}}$ is turned off and $\mathrm{S}$ is turned on with ZCS at $T_{1}$. The current of $\mathrm{D}^{\prime}$ is directed to the auxiliary circuit. $i_{L r}$ increases rapidly towards zero.

(c) Stage $3\left[T_{2}-T_{3}\right]: \quad i_{L r}$ returns to zero at $T_{2}$ and the antiparallel diode of $\mathrm{S}_{\mathrm{a}}$ is turned off naturally. $\mathrm{Lr}$ and $\mathrm{Cr}$ continue resonating and the positive $i_{L r}$ is conducted by $\mathrm{D}_{\mathrm{a}}^{\prime}$. $i_{L r}$ returns to zero and $\mathrm{D}_{\mathrm{a}}^{\prime}$ is turned off naturally at $T_{3}$.

(d) Stage $4\left[T_{3}-T_{4}\right]$ : It is a powering mode

(e) Stage $5\left[T_{4}-T_{5}\right]$ : Before $\mathrm{S}$ is turned off, $\mathrm{S}$ a is turned on again. $\mathrm{Lr}$ and $\mathrm{Cr}$ start resonating. When $i_{L r}$ increases from zero to peak and then decreases toward zero and changes direction and reaches $-I_{0}$ at $T_{5}$ and the antiparallel diode of $\mathrm{S}_{\mathrm{a}}$ becomes on.

(f) Stage $6\left[T_{5}-T_{6}\right]$ : At $T_{5} \quad i_{L r}$ reaches $-I_{0}$ and the current of $\mathrm{S}$ is reduced to zero, so $\mathrm{S}$ is turned off with ZCS. As $i_{L r}$ keeps decreasing, and flows through the antiparallel diode of $\mathrm{S}$.

(g) Stage $7\left[T_{6}-T_{7}\right]$ : At $T_{6}, i_{L r}$ reaches to $I_{\mathrm{o}}$ and the antiparallel diode of $\mathrm{S}$ stops conducting.

(h) Stage $8\left[T_{7}-T_{8}\right]:$ At $T_{7}, v_{C r}$ is discharged to zero and $D^{\prime}$ starts to conduct. The current in $D^{\prime}$ increases gradually.

(i) Stage $9\left[T_{8}-T_{9}\right]$ : It is a freewheeling mode via $\mathrm{D}^{\prime}$.

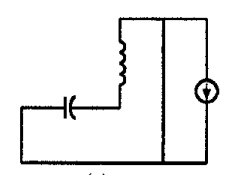

(a)

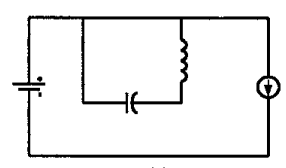

(c)

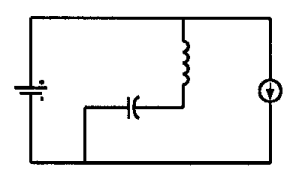

(e)

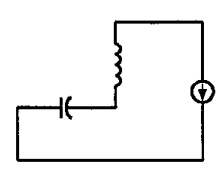

(g)

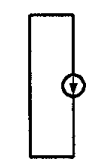

(i)

Fig. 8. Nine topological stages of bidirectional ZCT converter during motoring mode.
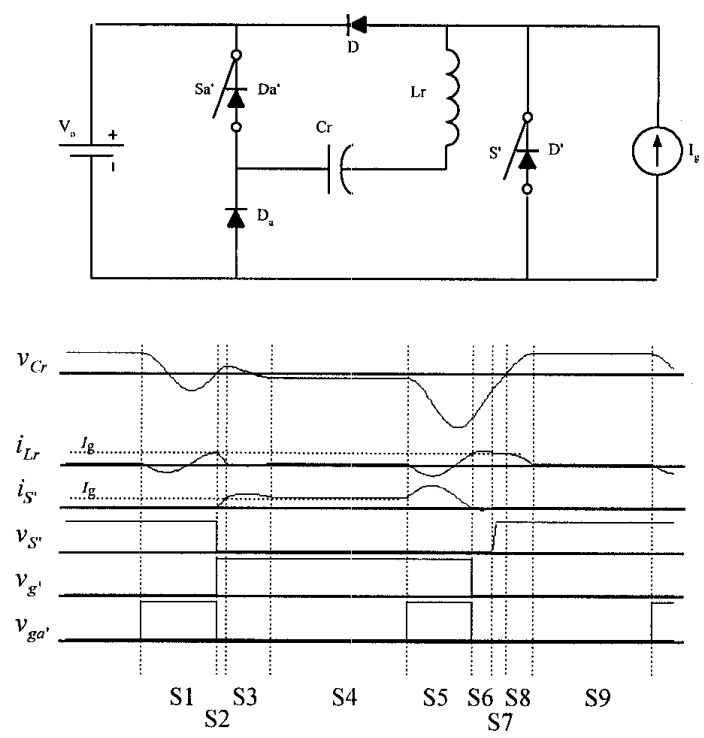

Fig. 9. Equivalent circuit and key waveforms of bidirectional ZCT converter during regenerating mode.

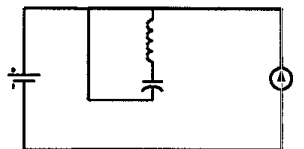

(a)

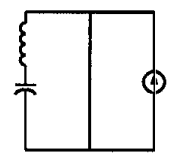

(c)

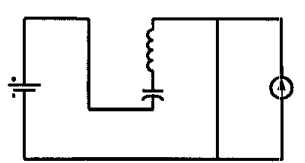

(e)

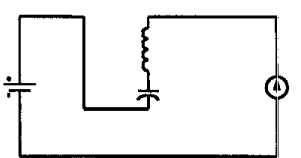

(g)

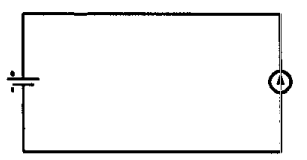

(i)

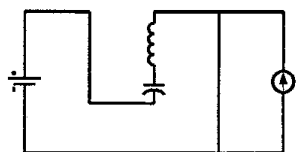

(b)

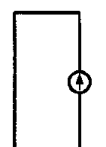

(d)

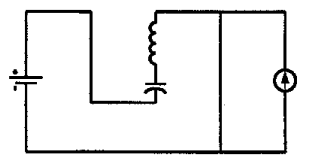

(f)

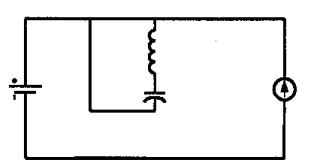

(h)
Fig. 10. Nine topological stages of bidirectional ZCT converter during regenerating mode. 


\subsection{Regenerating Mode (Figs. $9 \& 10$ )}

(a) Stage $1\left[T_{0}-T_{1}\right]: \quad \mathrm{S}_{\mathrm{a}}{ }^{\prime}$ is turned on and $\mathrm{Lr}$ and $\mathrm{Cr}$ start resonating. When $i_{L r}$ decreases from zero to negative peak and then increases toward zero and changes direction. $i_{L r}$ reaches $I_{\mathrm{g}}$ at $T_{1}$ and the antiparallel diode of $S_{a}{ }^{\prime}$ becomes on.

(b) Stage $2\left[T_{1}-T_{2}\right]: \quad S_{a}{ }^{\prime}$ is turned off and $S^{\prime}$ is turned on with ZCS at $T_{1}$. The current of D is directed to the auxiliary circuit. $i_{L r}$ decreases rapidly towards zero.

(c) Stage $3\left[T_{2}-T_{3}\right]: \quad i_{L r}$ returns to zero at $T_{2}$ and the antiparallel diode of $\mathrm{S}_{\mathrm{a}}{ }^{\prime}$ is turned off naturally. $\mathrm{Lr}$ and $\mathrm{Cr}$ continue resonating and the negative $i_{L r}$ is conducted by $\mathrm{D}_{\mathrm{a}}$. $i_{L r}$ returns to zero and $\mathrm{D}_{\mathrm{a}}$ is turned off naturally at $T_{3}$.

(d) Stage $4\left[T_{3}-T_{4}\right]$ : It is a freewheeling mode

(e) Stage $5\left[T_{4}-T_{5}\right]$ : Before $\mathrm{S}^{\prime}$ is turned off, $\mathrm{S}_{\mathrm{a}}{ }^{\prime}$ is turned on again. $\mathrm{Lr}$ and $\mathrm{Cr}$ start resonating. When $i_{L r}$ decreases from negative zero to peak and then increases toward zero and changes direction and reaches $I_{\mathrm{g}}$ at $T_{5}$ and the antiparallel diode of $\mathrm{S}_{\mathrm{a}}{ }^{\prime}$ becomes on.

(f) Stage $6\left[T_{5}-T_{6}\right]$ : At $T_{5}$ reaches $I_{\mathrm{g}}$ and the current of $S^{\prime}$ is reduced to zero, so $S^{\prime}$ is turned off with ZCS. As $i_{L r}$ keeps increasing, and flows through the antiparallel diode of S'.

(g) Stage $7\left[T_{6}-T_{7}\right]$ : At $T_{6}, i_{L r}$ falls to $I_{\mathrm{g}}$ and the antiparallel diode of $\mathrm{S}^{\prime}$ stops conducting.

(h) Stage $8\left[T_{7}-T_{8}\right]$ : At $T_{7}, v_{C r}$ is discharged to zero and $\mathrm{D}$ starts to conduct. The current in D increases gradually.

(i) Stage $9\left[T_{8}-T_{9}\right]$ : It is a powering mode via $\mathrm{D}$.

\section{SIMULATION AND EXPERIMENTAL RESULTS}

To verify the theoretical results, both bidirectional ZVT converter and bidirectional ZCT converter with parameters shown in Figs. $11 \& 12$ respectively are PSpice-simulated and hardware prototyped.

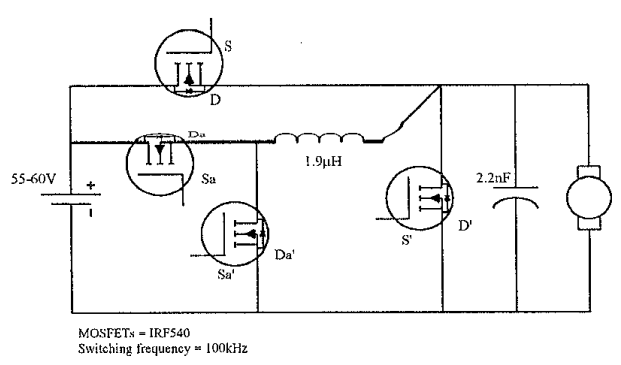

Fig. 11. Experimental bidirectional ZVT converter.

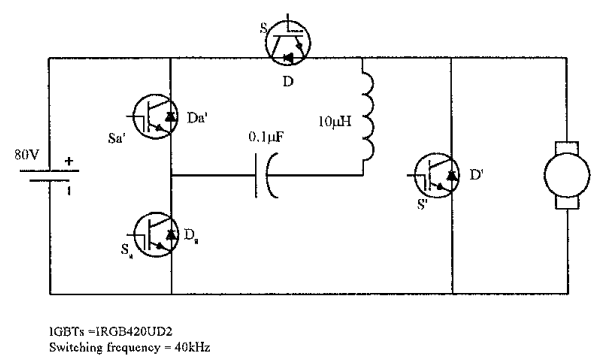

Fig. 12. Experimental bidirectional ZCT converter

\subsection{Bidirectional ZVT Converter (Figs. 14,14,17 \&18)}

From simulation results shown in Figs. 13 and 14, main transistors $\left(i_{S}, v_{S}\right.$ in Fig. 13 and $i_{S^{\prime}}, v_{S^{\prime}}$ in Fig. 14) and rectifiers $\left(i_{D}, v_{D^{\prime}}\right.$ in Fig. 13 and $i_{D}, v_{D}$ in Fig. 14) operate with ZVS in both motoring and regenerating modes, and they are subjected to the same voltage and current stresses as those in the PWM counterpart. From the experimental waveforms shown in Figs. 17 and 18, they closely agree with those theoretical waveforms, especially the main switches ( $S$ and $D^{\prime}$ for motoring while $S^{\prime}$ and D for regenerating) can always maintain ZVS operation.

\subsection{Bidirectional ZCT Converter (Figs. 15,16,19 \&20)}

From simulation results shown in Figs. 15 and 16, main and auxiliary transistors operate with ZCS in both motoring and regenerating modes, and they are subjected to the minimum voltage and current stresses. From the experimental waveforms shown in Figs. 19 and 20, they closely agree with those theoretical waveforms, especially the main and auxiliary switches can always maintain ZCS operation.

\section{CONCLUSION}

Two novel bidirectional soft transition converters for dc motor drives have been presented. The bidirectional zero-voltage-transition converter possesses the definite advantages that both main transistors and rectifiers can switch with zero-voltage switching (ZVS) and unity device stresses. While both the main and auxiliary switches of the bidirectional zoro-current-transition converter can operate with zero-current switching (ZCS). They have simple circuit topology and low cost, leading to achieve high switching frequency, high power density and high efficiency. Other key features are the use of the same resonant tank for both forward and backward power flows and the full utilization of all built-in diodes of the power switches, thus minimizing the overall hardware count and cost. 


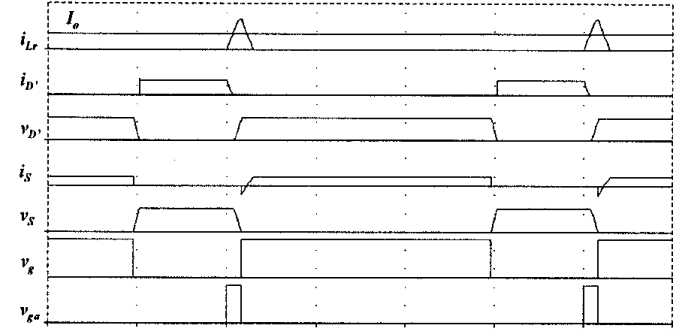

Fig. 13. PSpice simulation of bidirection ZVT converter at motoring mode.

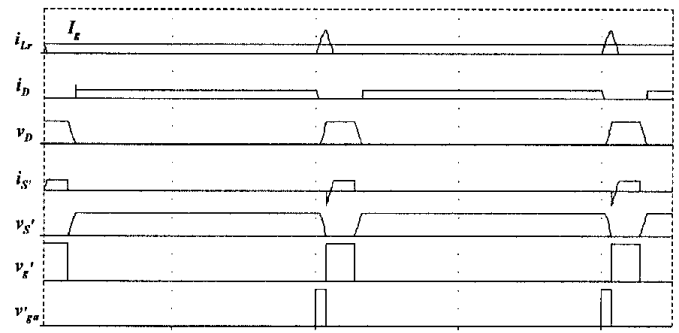

Fig. 14. PSpice simulation of bidirection ZVT converter at regenerating mode.

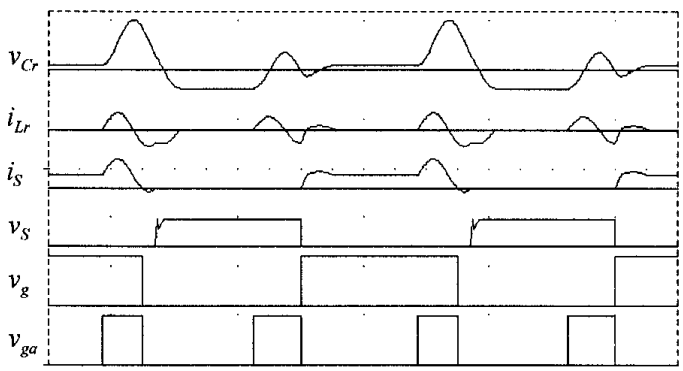

Fig. 15. PSpice simulation of bidirection ZCT converter at motoring mode.

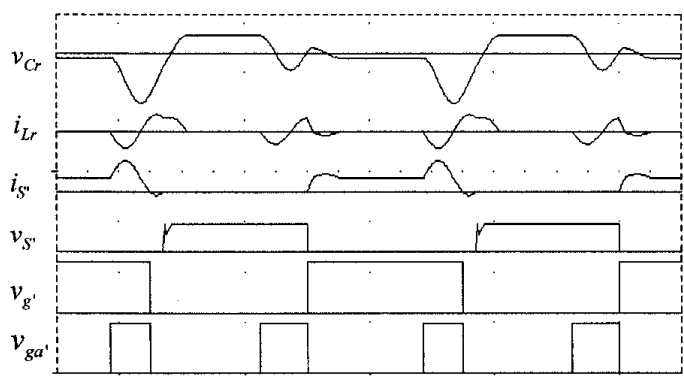

Fig. 16. PSpice simulation of bidirection ZCT converter at regenerating mode.

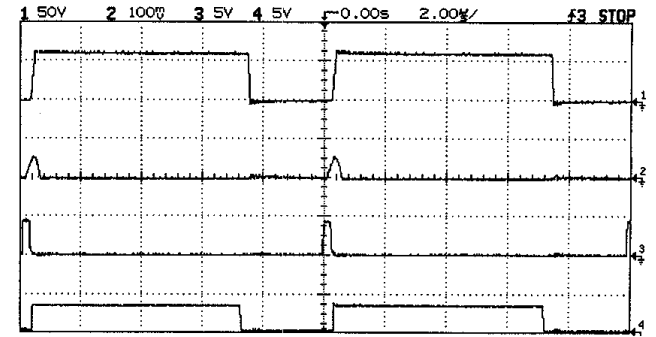

Fig. 17. Measured waveforms of bidirection ZVT converter at motoring (duty ratio $=0.7) ; \mathrm{v}_{\mathrm{D}^{\prime}}(50 \mathrm{~V} / \mathrm{div}) ; \mathrm{i}_{\mathrm{Lr}}(10 \mathrm{~A} / \mathrm{div}), \mathrm{v}_{\mathrm{ga}}, \mathrm{v}_{\mathrm{g}}$ (5V/div).

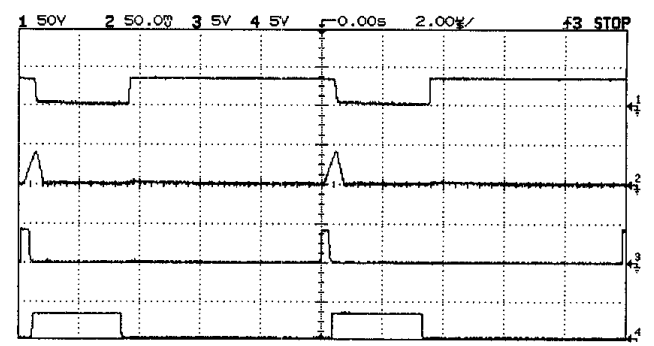

Fig. 18. Measured waveforms of bidirection ZVT converter at regenerating (duty ratio $=0.3) ; \mathbf{v}_{\mathrm{S}^{\prime}}(50 \mathrm{~V} / \mathrm{div})$ $\mathrm{i}_{\mathrm{Lr}}(5 \mathrm{~A} / \mathrm{div}), \mathrm{v}_{\mathrm{ga}}{ }^{\prime}, \mathrm{v}_{\mathrm{g}}{ }^{\prime}(5 \mathrm{~V} / \mathrm{div})$.

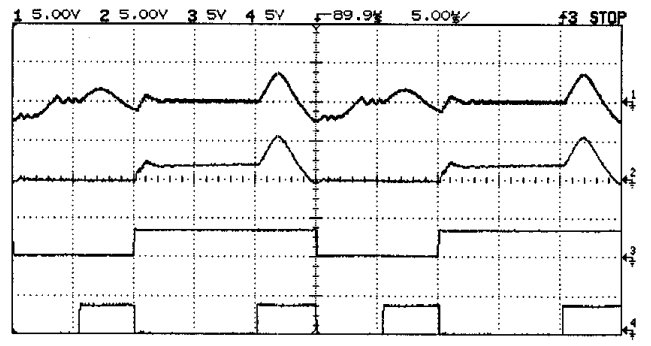

Fig. 19. Measured waveforms of bidirection ZCT converter at motoring (duty ratio $=0.6) ; \mathrm{i}_{\mathrm{S}}(10 \mathrm{~A} / \mathrm{div}) ; \mathrm{i}_{\mathrm{Lr}}(10 \mathrm{~A} / \mathrm{div}), \mathrm{v}_{\mathrm{ga}}, \mathrm{v}_{\mathrm{g}}$ (5V/div).

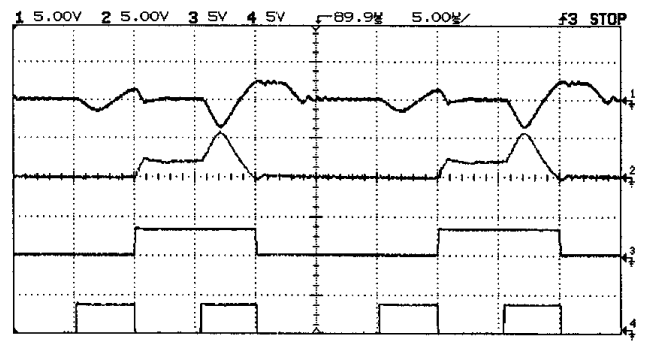

Fig. 20. Measured waveforms of bidirection ZCT converter at regenerating (duty ratio $=0.4) ; i_{S^{\prime}}(10 \mathrm{~A} / \mathrm{div})$;

$$
\mathrm{i}_{\mathrm{Lr}}(10 \mathrm{~A} / \mathrm{div}), \mathrm{v}_{\mathrm{ga}}{ }^{\prime}, \mathrm{v}_{\mathrm{g}}{ }^{\prime}(5 \mathrm{~V} / \mathrm{div}) \text {. }
$$




\section{ACKNOWLEDGMENT}

This work was supported and funded in part by the Committee on Research and Conference Grants, the University of Hong Kong.

\section{REFERENCES}

[1] D. Maksimović and S. Cuk, "Constant-frequency control of quasi-resonant converters," IEEE Trans. Power Electron., vol. 6, 1991, pp. 141150.

[2] C.C. Chan and K.T. Chau, "A new zero-voltageswitching dc/dc boost converter," IEEE Trans. Aero. Electron. Syst., vol. 29, 1993, pp. 125-134.

[3] G. Hua, C.S. Leu and F.C. Lee, "Novel zerovoltage-transition PWM converters," In Proceedings of VPEC Power Electronics Seminar, 1991, pp. 81-88.

[4] J.G. Cho, J.W. Baek, G.H. Rim and I. Kang, "Novel zero voltage transition PWM multi-phase converters," In Proceedings of IEEE APEC, 1996, pp. 500-506.

[5] H. Mao, F.C.Y. Lee, X. Zhou, H. Dai, M. Cosan and D. Boroyevich, "Improved zero-current transition converters for high power applications," IEEE Trans. Ind. Applicat., vol. 33, 1997, pp. 1220-1231.

[6] C.C. Chong, C.Y. Chan and C.F. Foo, "A quasiresonant converter-fed dc drive system," In Proceedings of EPE, 1993, pp. 372-377.

[7] K.T. Chau, T.W. Ching and C.C. Chan, "Constant-frequency multi-resonant converter-fed dc motor drives," In Proceedings of IECON, 1996, pp. 78-83. 